\title{
OPEN Effect of internet use and electronic game-play on academic performance of Australian children
}

\begin{abstract}
Md Irteja Islam ${ }^{1,2 \bowtie}$, Raaj Kishore Biswas ${ }^{3}$ \& Rasheda Khanam ${ }^{1}$
This study examined the association of internet use, and electronic game-play with academic performance respectively on weekdays and weekends in Australian children. It also assessed whether addiction tendency to internet and game-play is associated with academic performance. Overall, 1704 children of 11-17-year-olds from young minds matter (YMM), a cross-sectional nationwide survey, were analysed. The generalized linear regression models adjusted for survey weights were applied to investigate the association between internet use, and electronic-gaming with academic performance (measured by NAPLAN-National standard score). About $70 \%$ of the sample spent $>2 \mathrm{~h} /$ day using the internet and nearly $30 \%$ played electronic-games for $>2 \mathrm{~h} /$ day. Internet users during weekdays ( $>4 \mathrm{~h} /$ day) were less likely to get higher scores in reading and numeracy, and internet use on weekends ( $>2-4 \mathrm{~h} /$ day) was positively associated with academic performance. In contrast, $16 \%$ of electronic gamers were more likely to get better reading scores on weekdays compared to those who did not. Addiction tendency to internet and electronic-gaming is found to be adversely associated with academic achievement. Further, results indicated the need for parental monitoring and/or self-regulation to limit the timing and duration of internet use/electronic-gaming to overcome the detrimental effects of internet use and electronic game-play on academic achievement.
\end{abstract}

Over the past two decades, with the proliferation of high-tech devices (e.g. Smartphone, tablets and computers), both the internet and electronic games have become increasingly popular with people of all ages, but particularly with children and adolescents ${ }^{1-3}$. Recent estimates have shown that one in three under-18-year-olds across the world uses the Internet, and $75 \%$ of adolescents play electronic games daily in developed countries ${ }^{4-6}$. Studies in the United States reported that adolescents are occupied with over $11 \mathrm{~h}$ a day with modern electronic media such as computer/Internet and electronic games, which is more than they spend in school or with friends ${ }^{7,8}$. In Australia, it is reported that about $98 \%$ of children aged 15-17 years are among Internet users and $98 \%$ of adolescents play electronic games, which is significantly higher than the USA and Europe $\mathrm{e}^{9-12}$.

In recent times, the Internet and electronic games have been regarded as important, not just for better results at school, but also for self-expression, sociability, creativity and entertainment for children and adolescents ${ }^{13,14}$. For instance, $88 \%$ of $12-17$ year-olds in the USA considered the Internet as a useful mechanism for making progress in school ${ }^{15}$, and similarly, electronic gaming in children and adolescents may assist in developing skills such as decision-making, smart-thinking and coordination ${ }^{3,15}$.

On the other hand, evidence points to the fact that the use of the Internet and electronic games is found to have detrimental effects such as reduced sleeping time, behavioural problems (e.g. low self-esteem, anxiety, depression), attention problems and poor academic performance in adolescents ${ }^{1,5,12,16}$. In addition, excessive Internet usage and increased electronic gaming are found to be addictive and may cause serious functional impairment in the daily life of children and adolescents ${ }^{1,12,13,16}$. For example, the AU Kids Online survey ${ }^{17}$ reported that $50 \%$ of Australian children were more likely to experience behavioural problems associated with Internet use compared to children from 25 European countries (29\%) surveyed in the EU Kids Online study ${ }^{18}$, which is alarming ${ }^{12}$. These mixed results require an urgent need of understanding the effect of the Internet use and electronic gaming on the development of children and adolescents, particularly on their academic performance.

\footnotetext{
${ }^{1}$ Centre for Health Research and School of Commerce, University of Southern Queensland, Workstation 15, Room T450, Block T, Toowoomba, QLD 4350, Australia. ${ }^{2}$ Maternal and Child Health Division, International Centre for Diarrhoeal Disease Research, Bangladesh (icddr,b), Mohakhali, Dhaka 1212, Bangladesh. ${ }^{3}$ Transport and Road Safety (TARS) Research Centre, School of Aviation, University of New South Wales, Sydney, NSW 2052, Australia. ${ }^{\square}$ email: mdirteja.islam@usq.edu.au
} 
Despite many international studies and a smaller number in Australia ${ }^{12}$, several systematic limitations remain in the existing literature, particularly regarding the association of academic performance with the use of Internet and electronic games in children and adolescents ${ }^{13,16,19}$. First, the majority of the earlier studies have either relied on school grades or children's self assessments-which contain an innate subjectivity by the assessor; and have not considered the standardized tests of academic performance ${ }^{16,20-22}$. Second, most previous studies have tested the hypothesis in the school-based settings instead of canvassing the whole community, and cannot therefore adjust for sociodemographic confounders ${ }^{9,16}$. Third, most studies have been typically limited to smaller sample sizes, which might have reduced the reliability of the results ${ }^{9,16,23}$.

By considering these issues, this study aimed to investigate the association of internet usage and electronic gaming on a standardized test of academic performance-NAPLAN (The National Assessment Program-Literacy and Numeracy) among Australian adolescents aged 11-17 years using nationally representative data from the Second Australian Child and Adolescent Survey of Mental Health and Wellbeing-Young Minds Matter (YMM). It is hypothesized that the findings of this study will provide a population-wide, contextual view of excessive Internet use and electronic games played separately on weekdays and weekends by Australian adolescents, which may be beneficial for evidence-based policies.

\section{Results}

Subject demographics. Respondents who attended gave NAPLAN in $2008(\mathrm{~N}=4)$ and $2009(\mathrm{~N}=29)$ were removed from the sample due to smaller sample size, as later years (2010-2015) had over 100 samples yearly. The NAPLAN scores from 2008 might not align with a survey conducted in 2013. Further missing cases were deleted with the assumption that data were missing at random for unbiased estimates, which is common for large-scale surveys $^{24}$. From the initial survey of 2967 samples, 1704 adolescents were sampled for this study.

The sample characteristics were displayed in Table 1 . For example, distribution of daily average internet use was checked, showing that over $50 \%$ of the sampled adolescents spent $2-4 \mathrm{~h}$ on internet (Table 1 ). Although all respondents in the survey used internet, nearly $21 \%$ of them did not play any electronic games in a day and almost one in every three (33\%) adolescents played electronic games beyond the recommended time of $2 \mathrm{~h}$ per day. Girls had more addictive tendency to internet/game-play in compare to boys.

The mean scores for the three NAPLAN tests scores (reading, writing and numeracy) ranged from 520 to 600 . A gradual decline in average NAPLAN tests scores (reading, writing and numeracy) scores were observed for internet use over $4 \mathrm{~h}$ during weekdays, and over $3 \mathrm{~h}$ during weekends (Table 2). Table 2 also shows that adolescents who played no electronic games at all have better scores in writing compared to those who play electronic games. Moreover, Table 2 shows no particular pattern between time spent on gaming and NAPLAN reading and numeracy scores. Among the survey samples, 308 adolescents were below the national standard average.

Internet use and academic performance. Our results show that internet (non-academic use) use during weekdays, especially more than $4 \mathrm{~h}$, is negatively associated with academic performance (Table 3 ). For internet use during weekdays, all three models showed a significant negative association between time spent on internet and NAPLAN reading and numeracy scores. For example, in Model 1, adolescents who spent over $4 \mathrm{~h}$ on internet during weekdays are $15 \%$ and $17 \%$ less likely to get higher reading and numeracy scores respectively compared to those who spend less than $2 \mathrm{~h}$. Similar results were found in Model 2 and 3 (Table 3), when we adjusted other confounders. The variable addiction tendency to internet was found to be negatively associated with NAPLAN results. The adolescents who had internet addiction were $17 \%$ less and $14 \%$ less likely to score higher in reading and numeracy respectively than those without such problematic behaviour.

Internet use during weekends showed a positive association with academic performance (Table 4). For example, Model 1 in Table 4 shows that internet use during weekends was significant for reading, writing and national standard scores. Youths who spend around $2-4 \mathrm{~h}$ and over $4 \mathrm{~h}$ on the internet during weekends were $21 \%$ and $15 \%$ more likely to get a higher reading scores respectively compared to those who spend less than $2 \mathrm{~h}$ (Model 1 , Table 4). Similarly, in model 3, where the internet addiction of adolescents was adjusted, adolescents who spent 2-4 h on internet were 1.59 times more likely to score above the national standard. All three models of Table 4 confirmed that adolescents who spent $2-4 \mathrm{~h}$ on the internet during weekends are more likely to achieve better reading and writing scores and be at or above national standard compared to those who used the internet for less than $2 \mathrm{~h}$. Numeracy scores were unlikely to be affected by internet use. The results obtained from Model 3 should be treated as robust, as this is the most comprehensive model that accounts for unobserved characteristics. The addiction tendency to internet/game-play variable showed a negative association with academic performance, but this is only significant for numeracy scores.

Electronic gaming and academic performance. Time spent on electronic gaming during weekdays had no effect on the academic performance of writing and language but had significant association with reading scores (Model 2, Table 5). Model 2 of Table 5 shows that adolescents who spent 1-2 h on gaming during weekdays were $13 \%$ more likely to get higher reading scores compared to those who did not play at all. It was an interesting result that while electronic gaming during weekdays tended to show a positive effect on reading scores, internet use during weekdays showed a negative effect. Addiction tendency to internet/game-play had a negative effect; the adolescents who were addicted to the internet were $14 \%$ less likely to score more highly in reading than those without any such behaviour.

All three models from Table 6 confirm that time spent on electronic gaming over $2 \mathrm{~h}$ during weekends had a positive effect on readings scores. For example, the results of Model 3 (Table 6) showed that adolescents who spent more than $2 \mathrm{~h}$ on electronic gaming during weekdays were $16 \%$ more likely to have better reading scores compared to adolescents who did not play games at all. Playing electronic games during weekends was not found 


\begin{tabular}{|c|c|c|c|}
\hline \multirow[b]{2}{*}{ Variables } & Girls & Boys & Total \\
\hline & $\mathbf{N}(\%)$ & $\mathbf{N}(\%)$ & $\mathrm{N}(\%)$ \\
\hline \multicolumn{4}{|l|}{ Age $^{*}$} \\
\hline & $15.42(1.38)$ & $15.35(1.38)$ & $15.38(1.38)$ \\
\hline \multicolumn{4}{|c|}{ Household income } \\
\hline Low & $163(20)$ & $157(18.3)$ & $320(19.2)$ \\
\hline Medium & $377(46.3)$ & $404(47.2)$ & $781(46.7)$ \\
\hline High & $275(33.7)$ & $295(34.5)$ & $570(34.1)$ \\
\hline \multicolumn{4}{|c|}{ Primary carer's highest level of education } \\
\hline Bachelor & $268(32.9)$ & $287(33.5)$ & $555(33.2)$ \\
\hline Diploma & $304(37.3)$ & $317(37)$ & $621(37.2)$ \\
\hline Year-10_11 & $243(29.8)$ & $252(29.4)$ & $495(29.6)$ \\
\hline \multicolumn{4}{|l|}{ Family structure } \\
\hline Original & $517(63.4)$ & $576(67.3)$ & $1093(65.4)$ \\
\hline Step & $42(5.2)$ & $57(6.7)$ & $99(5.9)$ \\
\hline Blended & $62(7.6)$ & $54(6.3)$ & $116(6.9)$ \\
\hline Sole-parent/care & $183(22.5)$ & $160(18.7)$ & $343(20.5)$ \\
\hline Other & $11(1.3)$ & $9(1.1)$ & $20(1.2)$ \\
\hline \multicolumn{4}{|l|}{ Remoteness } \\
\hline Major city & $540(66.3)$ & $529(61.8)$ & $1069(64)$ \\
\hline Inner regional & $209(25.6)$ & $242(28.3)$ & $451(27)$ \\
\hline Outer regional & $60(7.4)$ & $73(8.5)$ & $133(8)$ \\
\hline Remote & $6(0.7)$ & $12(1.4)$ & $18(1.1)$ \\
\hline \multicolumn{4}{|c|}{ Primary carer's likelihood of serious mental illness (K6 score) } \\
\hline Likely & $23(2.8)$ & $21(2.5)$ & $44(2.6)$ \\
\hline Not likely & $792(97.2)$ & $835(97.5)$ & $1627(97.4)$ \\
\hline \multicolumn{4}{|c|}{ Primary carer's smoking status } \\
\hline No & $684(83.9)$ & $702(82)$ & $1386(82.9)$ \\
\hline Yes & $131(16.1)$ & $154(18)$ & $285(17.1)$ \\
\hline \multicolumn{4}{|c|}{ Risk of alcohol related harm by the primary carer } \\
\hline Risky & $212(26)$ & $246(28.7)$ & $458(27.4)$ \\
\hline None & $603(74)$ & $610(71.3)$ & $1213(72.6)$ \\
\hline \multicolumn{4}{|l|}{ Daily internet use } \\
\hline$\leq 2 \mathrm{~h}$ & $149(18.3)$ & $203(23.7)$ & $352(21.1)$ \\
\hline $2-4 \mathrm{~h}$ & $448(55)$ & $416(48.6)$ & $864(51.7)$ \\
\hline$>4 \mathrm{~h}$ & $218(26.7)$ & $237(27.7)$ & $455(27.2)$ \\
\hline \multicolumn{4}{|l|}{ Daily game-play } \\
\hline $0 \mathrm{~h}$ & $276(33.9)$ & $69(8.1)$ & $345(20.6)$ \\
\hline $1-2 \mathrm{~h}$ & $403(49.4)$ & $375(43.8)$ & 778 (46.6) \\
\hline$>2 \mathrm{~h}$ & $136(16.7)$ & $412(48.1)$ & $548(32.8)$ \\
\hline \multicolumn{4}{|c|}{ Addiction tendency to internet and/or game-play } \\
\hline Yes & $143(17.5)$ & $131(15.3)$ & $274(16.4)$ \\
\hline No & $672(82.5)$ & $725(84.7)$ & $1397(83.6)$ \\
\hline
\end{tabular}

Table 1. Sample characteristics. ${ }^{\star}$ Mean and SD.

to be statistically significant for writing and numeracy scores and national standard scores, although the odds ratios were positive. The results from all tables confirm that addiction tendency to internet/gaming is negatively associated with academic performance, although the variable is not always statistically significant.

\section{Discussion}

Building on past research on the effect of the internet use and electronic gaming in adolescents, this study examined whether Internet use and playing electronic games were associated with academic performance (i.e. reading, writing and numeracy) using a standardized test of academic performance (i.e. NAPLAN) in a nationally representative dataset in Australia. The findings of this study question the conventional belief ${ }^{9,25}$ that academic performance is negatively associated with internet use and electronic games, particularly when the internet is used for non-academic purpose.

In the current hi-tech world, many developed countries (e.g. the USA, Canada and Australia) have recommended that 5-17 year-olds limit electronic media (e.g. internet, electronic games) to $2 \mathrm{~h}$ per day for 


\begin{tabular}{|c|c|c|c|c|c|c|c|c|}
\hline \multirow[b]{2}{*}{ In hours } & \multicolumn{4}{|c|}{ Weekdays [Mean (SD)] } & \multicolumn{4}{|c|}{ Weekends [Mean (SD)] } \\
\hline & Sample size & Reading & Writing & Numeracy & Sample size & Reading & Writing & Numeracy \\
\hline \multicolumn{9}{|c|}{ Average daily internet use } \\
\hline 1 & 167 & $574.48(71.6)$ & $\begin{array}{l}541.78 \\
(104.63)\end{array}$ & \begin{tabular}{|l|}
592.16 \\
$(84.74)$
\end{tabular} & 140 & \begin{tabular}{|l|}
561.54 \\
$(69.55)$
\end{tabular} & $527.33(109.13)$ & $573.28(79.20)$ \\
\hline 2 & 406 & $\begin{array}{l}594.63 \\
(75.64)\end{array}$ & 569.75 (97.48) & $\begin{array}{l}598.82 \\
(73.02)\end{array}$ & 325 & \begin{tabular}{|l|}
580.04 \\
$(68.73)$
\end{tabular} & $557.43(85.58)$ & $589.34(70.14)$ \\
\hline 3 & 500 & $\begin{array}{l}582.11 \\
(65.44)\end{array}$ & $563.35(81.79)$ & $\begin{array}{l}586.45 \\
(67.02)\end{array}$ & 460 & $\begin{array}{l}594.42 \\
(68.33)\end{array}$ & $574.23(81.55)$ & $597.18(69.90)$ \\
\hline 4 & 291 & $\begin{array}{l}594.63 \\
(65.45)\end{array}$ & $570.61(88.31)$ & $\begin{array}{l}593.02 \\
(70.96)\end{array}$ & 331 & \begin{tabular}{|l|}
586.87 \\
$(71.66)$
\end{tabular} & $565.98(92.34)$ & $591.86(75.33)$ \\
\hline 5 & 119 & \begin{tabular}{|l|}
576.41 \\
$(63.18)$
\end{tabular} & $565.23(84.14)$ & $\begin{array}{l}581.25 \\
(76.59)\end{array}$ & 191 & \begin{tabular}{|l|}
588.36 \\
(ss68.35)
\end{tabular} & $569.43(94.09)$ & $590.03(73.04)$ \\
\hline 6 & 81 & $581.21(69.6)$ & $555.23(93.03)$ & $\begin{array}{l}585.36 \\
(64.48)\end{array}$ & 119 & \begin{tabular}{|l|}
585.26 \\
$(62.86)$
\end{tabular} & $560.08(86.42)$ & $587.22(74.73)$ \\
\hline 7 & 140 & \begin{tabular}{|l|}
571.07 \\
$(62.65)$
\end{tabular} & $546.63(84.00)$ & $\begin{array}{l}574.71 \\
(73.70)\end{array}$ & 138 & \begin{tabular}{|l|}
581.42 \\
$(63.41)$
\end{tabular} & $553.60(93.60)$ & $578.77(65.14)$ \\
\hline \multicolumn{9}{|c|}{ Average daily game-play } \\
\hline 0 & 355 & $\begin{array}{l}586.84 \\
(67.43)\end{array}$ & $578.45(84.22)$ & \begin{tabular}{|l|}
583.76 \\
$(68.63)$
\end{tabular} & 355 & \begin{tabular}{|l|}
586.84 \\
$(67.43)$
\end{tabular} & $578.45(84.22)$ & $583.76(68.63)$ \\
\hline 1 & 608 & $\begin{array}{l}593.92 \\
(67.61)\end{array}$ & $576.48(82.98)$ & $\begin{array}{l}602.54 \\
(74.76)\end{array}$ & 394 & $\begin{array}{l}590.08 \\
(67.46)\end{array}$ & $574.23(82.66)$ & $593.60(69.92)$ \\
\hline 2 & 398 & \begin{tabular}{|l|}
580.86 \\
$(73.11)$
\end{tabular} & $551.91(99.13)$ & $\begin{array}{l}583.02 \\
(71.94)\end{array}$ & 377 & $\begin{array}{l}581.67 \\
(75.99)\end{array}$ & $563.46(98.64)$ & $591.13(79.62)$ \\
\hline 3 & 195 & \begin{tabular}{|l|}
577.30 \\
$(61.29)$
\end{tabular} & $542.34(90.48)$ & $\begin{array}{l}586.41 \\
(67.23)\end{array}$ & 295 & $\begin{array}{l}586.07 \\
(66.18)\end{array}$ & $551.02(80.46)$ & $592.06(73.02)$ \\
\hline 4 & 69 & \begin{tabular}{|l|}
562.31 \\
$(69.17)$ \\
\end{tabular} & $516.22(70.88)$ & \begin{tabular}{|l|}
566.93 \\
$(64.47)$
\end{tabular} & 134 & \begin{tabular}{|l|}
580.04 \\
$(66.45)$
\end{tabular} & $540.57(107.64)$ & $593.29(72.75)$ \\
\hline 5 & 42 & $\begin{array}{l}583.09 \\
(75.94)\end{array}$ & $545.22(102.6)$ & $\begin{array}{l}584.92 \\
(81.16)\end{array}$ & 67 & \begin{tabular}{|l|}
582.21 \\
$(62.33)$
\end{tabular} & 529.96 (95.37) & $581.15(64.58)$ \\
\hline 6 & 7 & \begin{tabular}{|l|}
568.60 \\
$(53.89)$
\end{tabular} & $520.10(35.58)$ & $\begin{array}{l}562.44 \\
(45.88)\end{array}$ & 37 & $\begin{array}{l}598.60 \\
(62.53)\end{array}$ & $561.82(67.99)$ & $610.53(73.08)$ \\
\hline 7 & 30 & $\begin{array}{l}553.73 \\
(66.11)\end{array}$ & $\begin{array}{l}495.29 \\
(105.97)\end{array}$ & $\begin{array}{l}575.28 \\
(78.90)\end{array}$ & 45 & $\begin{array}{l}559.79 \\
(63.89)\end{array}$ & $510.79(97.96)$ & $559.96(52.86)$ \\
\hline
\end{tabular}

Table 2. Average NAPLAN scores for reading, writing and numeracy across average daily internet use and average daily game-play.

entertainment purposes, with concerns about the possible negative consequences of excessive use of electronic media ${ }^{14,26}$. However, previous research has often reported that children and adolescents spent more than the recommended time ${ }^{26}$. The present study also found similar results, that is, that about $70 \%$ of the sampled adolescents aged 11-17 spent more than $2 \mathrm{~h}$ per day on the Internet and nearly $30 \%$ spent more than 2 -h on electronic gaming in a day. This could be attributed to the increased availability of computers/smart-phones and the internet among under- $18 \mathrm{~s}^{12}$. For instance, $97 \%$ of Australian households with children aged less than 15 years accessed internet at home in 2016-2017 ${ }^{10}$; as a result, policymakers recommended that parents restrict access to screens (e.g. Internet and electronic games) in children's bedrooms, monitor children using screens, share screen hours with their children, and to act as role models by reducing their own screen time ${ }^{14}$.

This research has drawn attention to the fact that the average time spent using the internet, which is often more than $4 \mathrm{~h}$ during weekdays tends to be negatively associated with academic performance, especially a lower reading and numeracy score, while internet use of more than $2 \mathrm{~h}$ during weekends is positively associated with academic performance, particularly having a better reading and writing score and above national standard score. By dividing internet use and gaming by weekdays and weekends, this study find an answer to the mixed evidence found in previous literature ${ }^{9}$. The results of this study clearly show that the non-academic use of internet during weekdays, particularly, spending more than $4 \mathrm{~h}$ on internet is harmful for academic performance, whereas, internet use on the weekends is likely to incur a positive effect on academic performance. This result is consistent with a USA study that reported that internet use is positively associated with improved reading skills and higher scores on standardized tests ${ }^{13,27}$. It is also reported in the literature that academic performance is better among moderate users of the internet compared to non-users or high level users ${ }^{13,27}$, which was in line with the findings of this study. This may be due to the fact that the internet is predominantly a text-based format in which the internet users need to type and read to access most websites effectively ${ }^{13}$. The results of this study indicated that internet use is not harmful to academic performance if it is used moderately, especially, if ensuring very limited use on weekdays. The results of this study further confirmed that timing (weekdays or weekends) of internet use is a factor that needs to be considered.

Regarding electronic gaming, interestingly, the study found that the average time of gaming either in weekdays or weekends is positively associated with academic performance especially for reading scores. These results contradicted previous literatures ${ }^{1,13,19,27}$ that have reported negative correlation between electronic games and educational performance in high-school children. The results of this study were consistent with studies conducted 


\begin{tabular}{|c|c|c|c|c|c|c|c|c|}
\hline \multirow[t]{2}{*}{ Covariates } & \multicolumn{2}{|l|}{ Reading score ${ }^{*}$} & \multicolumn{2}{|l|}{ Writing score ${ }^{*}$} & \multicolumn{2}{|c|}{ Numeracy score ${ }^{*}$} & \multicolumn{2}{|c|}{ National standard score } \\
\hline & OR $(95 \% \mathrm{CI})$ & $p$ value & OR $(95 \% \mathrm{CI})$ & $p$ value & OR $(95 \% \mathrm{CI})$ & $p$ value & OR $(95 \% \mathrm{CI})$ & $p$ value \\
\hline \multicolumn{9}{|l|}{ Model $1^{\star *}$} \\
\hline \multicolumn{9}{|c|}{ Internet use (ref: $\leq 2 \mathrm{~h})$} \\
\hline $2-4 \mathrm{~h}$ & $\begin{array}{l}0.971(0.868 \\
1.086)\end{array}$ & 0.606 & $\begin{array}{l}0.999(0.894 \\
1.117)\end{array}$ & 0.989 & $\begin{array}{l}0.916(0.822 \\
1.02)\end{array}$ & 0.110 & $\begin{array}{l}1.076(0.78 \\
1.484)\end{array}$ & 0.657 \\
\hline$>4 \mathrm{~h}$ & \begin{tabular}{|l|}
$0.852(0.735$ \\
$0.987)$
\end{tabular} & 0.032 & $\begin{array}{l}0.981(0.856 \\
1.124)\end{array}$ & 0.783 & $\begin{array}{l}0.831(0.717 \\
0.964)\end{array}$ & 0.015 & $\begin{array}{l}1.055(0.714 \\
1.558)\end{array}$ & 0.790 \\
\hline \multicolumn{9}{|l|}{ Model 2*** } \\
\hline \multicolumn{9}{|c|}{ Internet use (ref: $\leq 2 \mathrm{~h})$} \\
\hline $2-4 \mathrm{~h}$ & \begin{tabular}{|l}
$0.968(0.867$ \\
$1.082)$
\end{tabular} & 0.567 & $\begin{array}{l}0.994(0.891 \\
1.11)\end{array}$ & 0.918 & $\begin{array}{l}0.911(0.82 \\
1.013)\end{array}$ & 0.086 & $\begin{array}{l}1.063(0.767 \\
1.471)\end{array}$ & 0.715 \\
\hline$>4 \mathrm{~h}$ & $\begin{array}{l}0.856 \text { (0.739, } \\
0.99)\end{array}$ & 0.037 & $\begin{array}{l}0.982(0.858 \\
1.124)\end{array}$ & 0.797 & \begin{tabular}{|l}
$0.835(0.721$ \\
$0.967)$
\end{tabular} & 0.016 & $\begin{array}{l}1.057(0.711 \\
1.569)\end{array}$ & 0.785 \\
\hline \multicolumn{9}{|l|}{ Model $3^{* * * *}$} \\
\hline \multicolumn{9}{|c|}{ Internet use (ref: $\leq 2 \mathrm{~h}$ ) } \\
\hline $2-4 \mathrm{~h}$ & $\begin{array}{l}0.948(0.847 \\
1.06)\end{array}$ & 0.348 & $\begin{array}{l}0.99(0.884 \\
1.108)\end{array}$ & 0.858 & \begin{tabular}{|l}
$0.896(0.805$ \\
$0.997)$
\end{tabular} & 0.044 & \begin{tabular}{|l}
$1.038(0.748$ \\
$1.442)$
\end{tabular} & 0.822 \\
\hline$>4 \mathrm{~h}$ & $\begin{array}{l}0.822(0.709 \\
0.953)\end{array}$ & 0.01 & $\begin{array}{l}0.974(0.849 \\
1.117)\end{array}$ & 0.709 & \begin{tabular}{|l}
$0.809(0.699$ \\
$0.936)$
\end{tabular} & 0.004 & $\begin{array}{l}1.015(0.683 \\
1.508)\end{array}$ & 0.943 \\
\hline $\begin{array}{l}\text { Addiction ten- } \\
\text { dency to internet } \\
\text { or game-play }\end{array}$ & \begin{tabular}{|l}
0.833 \\
$(0.728,0.954)$
\end{tabular} & 0.008 & \begin{tabular}{|l}
0.963 \\
$(0.841,1.102)$
\end{tabular} & 0.579 & \begin{tabular}{|l}
0.864 \\
$(0.755,0.987)$
\end{tabular} & 0.032 & $\begin{array}{l}0.831 \\
(0.558,1.239)\end{array}$ & 0.364 \\
\hline
\end{tabular}

Table 3. Generalized linear model fitted to various scores and national standard scores for weekdays internet use adjusting the behavioral and sociodemographic factors, as well as survey weights. ${ }^{\star}$ Standardized (mean of 0 and a standard deviation of 1). ${ }^{*}$ The model was adjusted for age and sex of the child, household income, primary carer's education and family type. ${ }^{* \star}$ Model 2 was adjusted for age and sex of the child, household income, primary carer's education, family type, remoteness, primary carer's mental health, smoking and drinking habits. ${ }^{* * *}$ Model 3 was adjusted for age and sex of the child, household income, primary carer's education, family type, remoteness, primary carer's mental health, smoking and drinking habits and internet addiction of the child.

in the USA, Europe and other countries that claimed a positive correlation between gaming and academic performance, especially in numeracy and reading skills ${ }^{28,29}$. This is may be due to the fact that the instructions for playing most of the electronic games are text-heavy and many electronic games require gamers to solve puzzles ${ }^{9,30}$. The literature also found that playing electronic games develops cognitive skills (e.g. mental rotation abilities, dexterity), which can be attributable to better academic achievement ${ }^{31,32}$.

Consistent with previous research findings ${ }^{33-36}$, the study also found that adolescents who had addiction tendency to internet usage and/or electronic gaming were less likely to achieve higher scores in reading and numeracy compared to those who had not problematic behaviour. Addiction tendency to Internet/gaming among adolescents was found to be negatively associated with overall academic performance compared to those who were not having addiction tendency, although the variables were not always statistically significant. This is mainly because adolescents' skipped school and missed classes and tuitions, and provide less effort to do homework due to addictive internet usage and electronic gaming ${ }^{19,35}$. The results of this study indicated that parental monitoring and/ or self-regulation (by the users) regarding the timing and intensity of internet use/gaming are essential to outweigh any negative effect of internet use and gaming on academic performance.

Although the present study uses a large nationally representative sample and advances prior research on the academic performance among adolescents who reported using the internet and playing electronic games, the findings of this study also have some limitations that need to be addressed. Firstly, adolescents who reported on the internet use and electronic games relied on self-reported child data without any screening tests or any external validation and thus, results may be overestimated or underestimated. Second, the study primarily addresses the internet use and electronic games as distinct behaviours, as the YMM survey gathered information only on the amount of time spent on internet use and electronic gaming, and included only a few questions related to addiction due to resources and time constraints and did not provide enough information to medically diagnose internet/gaming addiction. Finally, the cross-sectional research design of the data outlawed evaluation of causality and temporality of the observed association of internet use and electronic gaming with the academic performance in adolescents.

\section{Conclusion}

This study found that the average time spent on the internet on weekends and electronic gaming (both in weekdays and weekends) is positively associated with academic performance (measured by NAPLAN) of Australian adolescents. However, it confirmed a negative association between addiction tendency (internet use or electronic gaming) and academic performance; nonetheless, most of the adolescents used the internet and played electronic games more than the recommended 2-h limit per day. The study also revealed that further research is required 


\begin{tabular}{|c|c|c|c|c|c|c|c|c|}
\hline & \multicolumn{2}{|c|}{ Reading score* } & \multicolumn{2}{|l|}{ Writing score ${ }^{\star}$} & \multicolumn{2}{|l|}{ Numeracy score ${ }^{*}$} & \multicolumn{2}{|c|}{ National standard score } \\
\hline & \begin{tabular}{|l|} 
OR $(95 \% \mathrm{CI})$ \\
\end{tabular} & $p$ value & OR $(95 \% \mathrm{CI})$ & $p$ value & OR $(95 \% \mathrm{CI})$ & $p$ value & OR $(95 \% \mathrm{CI})$ & $p$ value \\
\hline \multicolumn{9}{|l|}{ Model 1** } \\
\hline \multicolumn{9}{|c|}{ Internet use (ref: $\leq 2 \mathrm{~h}$ ) } \\
\hline $2-4 \mathrm{~h}$ & $\begin{array}{l}\text { 1.211 (1.071, } \\
1.369)\end{array}$ & 0.002 & \begin{tabular}{|l|}
1.237 \\
$(1.097,1.394)$
\end{tabular} & 0.001 & \begin{tabular}{|l|}
1.094 \\
$(0.971,1.233)$
\end{tabular} & 0.139 & $1.677(1.196,2.35)$ & 0.003 \\
\hline$>4 \mathrm{~h}$ & $\begin{array}{l}1.15(1.003 \\
1.319)\end{array}$ & 0.046 & $\begin{array}{l}1.141(0.998 \\
1.306)\end{array}$ & 0.054 & $\begin{array}{l}0.971(0.849 \\
1.112)\end{array}$ & 0.673 & $\begin{array}{l}1.287(0.888, \\
1.865)\end{array}$ & 0.183 \\
\hline \multicolumn{9}{|l|}{ Model $2^{* * *}$} \\
\hline \multicolumn{9}{|c|}{ Internet use (ref: $\leq 2 \mathrm{~h})$} \\
\hline $2-4 \mathrm{~h}$ & $\begin{array}{l}1.182(1.046 \\
1.336)\end{array}$ & 0.007 & $\begin{array}{l}1.205(1.07 \\
1.356)\end{array}$ & 0.002 & $\begin{array}{l}.055(0.938 \\
1.187)\end{array}$ & 0.372 & $\begin{array}{l}1.61(1.139 \\
2.275)\end{array}$ & 0.007 \\
\hline$>4 \mathrm{~h}$ & $\begin{array}{l}1.146(1.00 \\
1.313)\end{array}$ & 0.05 & $\begin{array}{l}1.129(0.988 \\
1.29)\end{array}$ & 0.074 & $\begin{array}{l}0.955(0.836 \\
1.092)\end{array}$ & 0.504 & $\begin{array}{l}.281(0.875 \\
1.876)\end{array}$ & 0.203 \\
\hline \multicolumn{9}{|l|}{ Model 3****} \\
\hline \multicolumn{9}{|c|}{ Internet use (ref: $\leq 2 \mathrm{~h}$ ) } \\
\hline $2-4 \mathrm{~h}$ & $\begin{array}{l}1.171 \\
(1.036,1.323)\end{array}$ & 0.011 & \begin{tabular}{|l|}
1.204 \\
$(1.068,1.357)$
\end{tabular} & 0.002 & \begin{tabular}{|l|}
1.045 \\
$(0.929,1.175)$
\end{tabular} & 0.468 & \begin{tabular}{|l|}
1.591 \\
$(1.123,2.253)$
\end{tabular} & 0.009 \\
\hline$>4 \mathrm{~h}$ & \begin{tabular}{|l|}
1.102 \\
$(0.958,1.269)$
\end{tabular} & 0.174 & $\begin{array}{l}1.124 \\
(0.975,1.295)\end{array}$ & 0.106 & $0.917(0.8,1.051)$ & 0.213 & $1.223(0.827,1.81)$ & 0.313 \\
\hline $\begin{array}{l}\text { Addiction ten- } \\
\text { dency to internet } \\
\text { or game-play }\end{array}$ & \begin{tabular}{|l|}
0.879 \\
$(0.765,1.009)$
\end{tabular} & 0.068 & \begin{tabular}{|l|}
0.985 \\
$(0.857,1.133)$
\end{tabular} & 0.837 & $\begin{array}{l}0.872 \\
(0.760,1.002)\end{array}$ & 0.053 & $0.848(0.566,1.27)$ & 0.423 \\
\hline
\end{tabular}

Table 4. Generalized linear model fitted to various scores and national standard scores for weekends internet use adjusting the behavioural and sociodemographic factors, as well as survey weights. ${ }^{\star}$ Standardized (mean of 0 and a standard deviation of 1). ${ }^{*}$ The model was adjusted for age and sex of the child, household income, primary carer's education and family type. ${ }^{* \star}$ Model 2 was adjusted for age and sex of the child, household income, primary carer's education, family type, remoteness, primary carer's mental health, smoking and drinking habits. ${ }^{* * *}$ Model 3 was adjusted for age and sex of the child, household income, primary carer's education, family type, remoteness, primary carer's mental health, smoking and drinking habits and internet addiction of the child.

on the development and implementation of interventions aimed at improving parental monitoring and fostering users' self-regulation to restrict the daily usage of the internet and/or electronic games.

\section{Methods}

Data description. Young minds matter (YMM) was an Australian nationwide cross-sectional survey, on children aged 4-17 years conducted in 2013-2014 37 . Out of the initial 76,606 households approached, a total of 6,310 parents/caregivers (eligible household response rate 55\%) of 4-17 year-old children completed a structured questionnaire via face to face interview and 2967 children aged 11-17 years (eligible children response rate $89 \%$ ) completed a computer-based self-reported questionnaire privately at home ${ }^{37}$.

Area based sampling was used for the survey. A total of 225 Statistical Area 1 (defined by Australian Bureau of Statistics) areas were selected based on the 2011 Census of Population and Housing. They were stratified by state/ territory and by metropolitan versus non-metropolitan (rural/regional) to ensure proportional representation of geographic areas across Australia ${ }^{38}$. However, a small number of samples were excluded, based on most remote areas, homeless children, institutional care and children living in households where interviews could not be conducted in English. The details of the survey and methodology used in the survey can be found in Lawrence et al. ${ }^{37}$.

Following informed consent (both written and verbal) from the primary carers (parents/caregivers), information on the National Assessment Program-Literacy and Numeracy (NAPLAN) of the children and adolescents were also added to the YMM dataset. The YMM survey is ethically approved by the Human Research Ethics Committee of the University of Western Australia and by the Australian Government Department of Health. In addition, the authors of this study obtained a written approval from Australian Data Archive (ADA) Dataverse to access the YMM dataset. All the researches were done in accordance with relevant ADA Dataverse guidelines and policy/regulations in using YMM datasets.

Variables. Outcome variables. The NAPLAN, conducted annually since 2008, is a nationwide standardized test of academic performance for all Australian students in Years 3, 5, 7 and 9 to assess their skills in reading, writing numeracy, grammar and spelling ${ }^{39,40}$. NAPLAN scores from 2010 to 2015, reported by YMM, were used as outcome variables in the models; while NAPLAN data of $2008(\mathrm{~N}=4)$ and $2009(\mathrm{~N}=29)$ were excluded for this study in order to reduce the time lag between YMM survey and the NAPLAN test. The NAPLAN gives point-in-time standardized scores, which provide the scope to compare children's academic performance over time ${ }^{40,41}$. The NAPLAN tests are one component of the evaluation and grading phase of each school, and do not substitute for the comprehensive, consistent evaluations provided by teachers on the performance of each student $^{39,41}$. All four domains-reading, writing, numeracy and language conventions (grammar and spelling) 


\begin{tabular}{|c|c|c|c|c|c|c|c|c|}
\hline \multirow[b]{2}{*}{ Covariates } & \multicolumn{2}{|l|}{ Reading score ${ }^{\star}$} & \multicolumn{2}{|l|}{ Writing score } & \multicolumn{2}{|l|}{ Numeracy score } & \multicolumn{2}{|c|}{ National standard score } \\
\hline & OR $(95 \% \mathrm{CI})$ & $p$ value & OR $(95 \% \mathrm{CI})$ & $p$ value & OR $(95 \% \mathrm{CI})$ & $p$ value & OR $(95 \% \mathrm{CI})$ & $p$ value \\
\hline \multicolumn{9}{|l|}{ Model $1^{* *}$} \\
\hline \multicolumn{9}{|c|}{ Game-play (ref: No game/ 0 h) } \\
\hline $1-2 \mathrm{~h}$ & \begin{tabular}{|l|}
1.121 \\
$(0.989,1.271)$
\end{tabular} & 0.075 & \begin{tabular}{|l|}
1.089 \\
$(0.961,1.234)$
\end{tabular} & 0.181 & $1.074(0.954,1.21)$ & 0.239 & \begin{tabular}{|l|}
1.188 \\
$(0.779,1.811)$
\end{tabular} & 0.423 \\
\hline$>2 \mathrm{~h}$ & $1.017(0.86,1.203)$ & 0.843 & $0.957(0.81,1.131)$ & 0.607 & $0.872(0.746,1.02)$ & 0.086 & \begin{tabular}{|l|}
0.753 \\
$(0.467,1.215)$
\end{tabular} & 0.245 \\
\hline \multicolumn{9}{|l|}{ Model 2*** } \\
\hline \multicolumn{9}{|c|}{ Game-play (ref: No game/ 0 h) } \\
\hline $1-2 \mathrm{~h}$ & $1.132(1,1.282)$ & 0.05 & \begin{tabular}{|l|}
1.084 \\
$(0.962,1.222)$
\end{tabular} & 0.184 & \begin{tabular}{|l|}
1.103 \\
$(0.977,1.245)$
\end{tabular} & 0.113 & \begin{tabular}{|l|}
1.234 \\
$(0.803,1.897)$
\end{tabular} & 0.337 \\
\hline$>2 \mathrm{~h}$ & \begin{tabular}{|l|}
1.044 \\
$(0.885,1.232)$
\end{tabular} & 0.609 & $0.891(0.763,1.04)$ & 0.144 & \begin{tabular}{|l|}
0.985 \\
$(0.838,1.158)$
\end{tabular} & 0.857 & \begin{tabular}{|l|}
0.803 \\
$(0.492,1.309)$
\end{tabular} & 0.379 \\
\hline \multicolumn{9}{|l|}{ Model 3****} \\
\hline \multicolumn{9}{|c|}{ Game-play (ref: No game/ 0 h) } \\
\hline $1-2 \mathrm{~h}$ & \begin{tabular}{|l|}
1.124 \\
$(0.992,1.274)$
\end{tabular} & 0.066 & \begin{tabular}{|l|}
1.081 \\
$(0.959,1.218)$
\end{tabular} & 0.201 & $1.097(0.971,1.24)$ & 0.138 & \begin{tabular}{|l|}
1.218 \\
$(0.793,1.871)$
\end{tabular} & 0.367 \\
\hline$>2 \mathrm{~h}$ & \begin{tabular}{|l|}
1.011 \\
$(0.855,1.195)$
\end{tabular} & 0.897 & \begin{tabular}{|l|}
0.878 \\
$(0.753,1.024)$
\end{tabular} & 0.099 & \begin{tabular}{|l|}
0.961 \\
$(0.817,1.131)$
\end{tabular} & 0.632 & \begin{tabular}{|l|}
0.757 \\
$(0.461,1.244)$
\end{tabular} & 0.273 \\
\hline $\begin{array}{l}\text { Addiction ten- } \\
\text { dency to internet } \\
\text { or game-play }\end{array}$ & \begin{tabular}{|l}
0.856 \\
$(0.748,0.979)$
\end{tabular} & 0.023 & \begin{tabular}{|l}
0.935 \\
$(0.820,1.065)$
\end{tabular} & 0.311 & $\begin{array}{l}0.887 \\
(0.774,1.015)\end{array}$ & 0.082 & $\begin{array}{l}0.751 \\
(0.497,1.135)\end{array}$ & 0.174 \\
\hline
\end{tabular}

Table 5. Generalized linear model fitted to various scores and national standard scores for weekdays gameplay adjusting the behavioural and sociodemographic factors, as well as survey weights. ${ }^{\star}$ Standardized (mean of 0 and a standard deviation of 1 ). ${ }^{* *}$ The model was adjusted for age and sex of the child, household income, primary carer's education and family type. ${ }^{* \star}$ Model 2 was adjusted for age and sex of the child, household income, primary carer's education, family type, remoteness, primary carer's mental health, smoking and drinking habits. ${ }^{* * *}$ Model 3 was adjusted for age and sex of the child, household income, primary carer's education, family type, remoteness, primary carer's mental health, smoking and drinking habits and internet addiction of the child.

are in continuous scales in the dataset. The scores are given based on a series of tests; details can be found $\mathrm{in}^{42}$. The current study uses only reading, writing and numeracy scores to measure academic performance.

In this study, the National standard score is a combination of three variables: whether the student meets the national standard in reading, writing and numeracy. Based on national average score, a binary outcome variable is also generated. One category is 'below standard' if a child scores at least one standard deviation (one below scores) from the national standard in reading, writing and numeracy, and the rest is 'at/above standard'.

Independent variables. Internet use and electronic gaming. In the YMM survey, owing to the scope of the survey itself, an extensive set of questions about internet usage and electronic gaming could not be included. Internet usage omitted the time spent in academic purposes and/or related activities. Playing electronic games included playing games on a gaming console (e.g. PlayStation, Xbox, or similar console ) online or using a computer, or mobile phone, or a handled device ${ }^{12}$. The primary independent covariates were average internet use per day and average electronic game-play in hours per day. A combination of hours on weekdays and weekends was separately used in the models. These variables were based on a self-assessed questionnaire where the youths were asked questions regarding daily time spent on the Internet and electronic game-play, specifically on either weekends or weekdays. Since, internet use/game-play for a maximum of $2 \mathrm{~h} /$ day is recommended for children and adolescents aged between 5 and 17 years in many developed countries including Australia ${ }^{14,26}$; therefore, to be consistent with the recommended time we preferred to categorize both the time variables of internet use and gaming into three groups with an interval of $2 \mathrm{~h}$ each. Internet use was categorized into three groups: (a) $\leq 2 \mathrm{~h}$ ), (b) 2-4 h, and (c) $>4 \mathrm{~h}$. Similar questions were asked for game-play h. The sample distribution for electronic game-play was skewed; therefore, this variable was categorized into three groups: (a) no game-play $(0 \mathrm{~h}),(\mathrm{b})$ $1-2 \mathrm{~h}$, and $(\mathrm{c})>2 \mathrm{~h}$.

Other covariates. Family structure and several sociodemographic variables were used in the models to adjust for the differences in individual characteristics, parental inputs and tastes, household characteristics and place of residence. Individual characteristics included age (continuous) and sex of the child (boys, girls) and addiction tendency to internet use and/or game-play of the adolescent. Addiction tendency to internet/gameplay was a binary independent variable. It was a combination of five behavioural questions relating to: whether the respondent avoided eating/sleeping due to internet use or game-play; feels bothered when s/he cannot access internet or play electronic games; keeps using internet or playing electronic games even when s/he is not really interested; spends less time with family/friends or on school works due to internet use or game-play; and unsuccessfully tries to spend less time on the internet or playing electronic games. There were four options for each 


\begin{tabular}{|c|c|c|c|c|c|c|c|c|}
\hline & \multicolumn{2}{|l|}{ Reading score ${ }^{*}$} & \multicolumn{2}{|l|}{ Writing score ${ }^{*}$} & \multicolumn{2}{|l|}{ Numeracy score ${ }^{\star}$} & \multicolumn{2}{|c|}{ National standard score } \\
\hline & OR $(95 \% \mathrm{CI})$ & $p$ value & OR $(95 \% \mathrm{CI})$ & $p$ value & OR $(95 \% \mathrm{CI})$ & $p$ value & OR $(95 \% \mathrm{CI})$ & $p$ value \\
\hline \multicolumn{9}{|l|}{ Model $1^{* *}$} \\
\hline \multicolumn{9}{|c|}{ Game-play (ref: No game/ 0 h) } \\
\hline $1-2 \mathrm{~h}$ & \begin{tabular}{|l|}
1.064 \\
$(0.935,1.212)$
\end{tabular} & 0.344 & \begin{tabular}{|l|}
1.045 \\
$(0.925,1.181)$
\end{tabular} & 0.479 & $1.058(0.93,1.202)$ & 0.392 & \begin{tabular}{|l|}
1.127 \\
$(0.738,1.722)$
\end{tabular} & 0.579 \\
\hline$>2 \mathrm{~h}$ & $1.172(1.01,1.359)$ & 0.036 & $\begin{array}{l}1.001 \\
(0.869,1.153)\end{array}$ & 0.985 & $1.068(0.92,1.239)$ & 0.386 & \begin{tabular}{|l}
0.953 \\
$(0.597,1.522)$
\end{tabular} & 0.841 \\
\hline \multicolumn{9}{|l|}{ Model 2***} \\
\hline \multicolumn{9}{|c|}{\begin{tabular}{|l} 
Game-play (ref: No game/ 0 h) \\
\end{tabular}} \\
\hline $1-2 \mathrm{~h}$ & $1.08(0.95,1.228)$ & 0.241 & \begin{tabular}{|l|}
1.059 \\
$(0.937,1.197)$
\end{tabular} & 0.361 & $1.077(0.951,1.22)$ & 0.245 & \begin{tabular}{|l|}
1.179 \\
$(0.765,1.816)$
\end{tabular} & 0.455 \\
\hline$>2 \mathrm{~h}$ & \begin{tabular}{|l|}
1.186 \\
$(1.025,1.372)$
\end{tabular} & 0.022 & $1.01(0.878,1.162)$ & 0.885 & \begin{tabular}{|l|}
1.082 \\
$(0.936,1.249)$
\end{tabular} & 0.287 & \begin{tabular}{|l|}
0.998 \\
$(0.619,1.608)$
\end{tabular} & 0.992 \\
\hline \multicolumn{9}{|l|}{ Model 3****} \\
\hline \multicolumn{9}{|c|}{ Game-play (ref: No game/ 0 h) } \\
\hline $1-2 \mathrm{~h}$ & \begin{tabular}{|l|}
1.077 \\
$(0.946,1.224)$
\end{tabular} & 0.262 & \begin{tabular}{|l|}
1.058 \\
$(0.936,1.196)$
\end{tabular} & 0.369 & \begin{tabular}{|l|}
1.074 \\
$(0.948,1.217)$
\end{tabular} & 0.263 & \begin{tabular}{|l|}
1.172 \\
$(0.761,1.806)$
\end{tabular} & 0.471 \\
\hline$>2 \mathrm{~h}$ & $1.16(1.002,1.343)$ & 0.047 & \begin{tabular}{|l|}
1.003 \\
$(0.872,1.153)$
\end{tabular} & 0.969 & \begin{tabular}{|l|}
1.062 \\
$(0.918,1.229)$
\end{tabular} & 0.417 & \begin{tabular}{|l|}
0.957 \\
$(0.592,1.548)$
\end{tabular} & 0.859 \\
\hline $\begin{array}{l}\text { Addiction ten- } \\
\text { dency to internet } \\
\text { or game-play }\end{array}$ & \begin{tabular}{|l}
0.887 \\
$(0.776,1.013)$
\end{tabular} & 0.077 & $0.96(0.841,1.095)$ & 0.540 & $\begin{array}{l}0.906 \\
(0.791,1.038)\end{array}$ & 0.154 & \begin{tabular}{|l|}
0.793 \\
$(0.529,1.187)$
\end{tabular} & 0.260 \\
\hline
\end{tabular}

Table 6. Generalized linear model fitted to various scores and national standard scores for weekends gameplay adjusting the behavioural and sociodemographic factors, as well as survey weights. ${ }^{\star}$ Standardized (mean of 0 and a standard deviation of 1). ${ }^{\star *}$ The model was adjusted for age and sex of the child, household income, primary carer's education and family type. ${ }^{* \star}$ Model 2 was adjusted for age and sex of the child, household income, primary carer's education, family type, remoteness, primary carer's mental health, smoking and drinking habits. ${ }^{* * *}$ Model 3 was adjusted for age and sex of the child, household income, primary carer's education, family type, remoteness, primary carer's mental health, smoking and drinking habits and internet addiction of the child.

question: never/almost never; not very often; fairly often; and very often. A binary covariate was simulated, where if any four out of five behaviours were reported as for example, fairly often or very often, then it was considered that the respondent had addictive tendency.

Household characteristics included household income (low, medium, high), family type (original, step, blended, sole parent/primary carer, other) ${ }^{43}$ and remoteness (major cities, inner regional, outer regional, remote/ very remote). Parental inputs and taste included education of primary carer (bachelor, diploma, year 10/11), primary carer's likelihood of serious mental illness (K6 score -likely; not likely); primary carer's smoking status (no, yes); and risk of alcoholic related harm by the primary carer (risky, none).

Statistical analysis. Descriptive statistics of the sample and distributions of the outcome variables were initially assessed. Based on these distributions, the categorization of outcome variables was conducted, as mentioned above. For formal analysis, generalized linear regression models (GLMs) ${ }^{44}$ were used, adjusting for the survey weights, which allowed for generalization of the findings. As NAPLAN scores of three areas-reading, writing and numeracy-were continuous variables, linear models were fitted to daily average internet time and electronic game play time. The scores were standardized (mean $=0, S D=1)$ for model fitness. The binary logistic model was fitted for the dichotomized national standard outcome variable. Separate models were estimated for internet and electronic gaming on weekends and weekdays.

We estimated three different models, where models varied based on covariates used to adjust the GLMs. Model 1 was adjusted for common sociodemographic factors including age and sex of the child, household income, education of primary carer's and family type ${ }^{43}$. However, the results of this model did not account for some unobserved household characteristics (e.g. taste, preferences) that are unobserved to the researcher and are arguably correlated with potential outcomes. The effects of unobserved characteristics were reduced by using a comprehensive set of observable characteristics ${ }^{45,46}$ that were available in YMM data. The issue of unobserved characteristics was addressed by estimating two additional models that include variables by including household characteristics such as parental taste, preference and inputs, and child characteristics in the model. In addition to the variables in Model 1, Model 2 included remoteness, primary carer's mental health status, smoking status and risk of alcoholic related harm by the primary carer. Model 3 further included internet/game addiction of the adolescent in addition to all the covariates in Model 2. Model 3 was expected to account for a child's level of unobserved characteristics as the children who were addicted to internet/games were different from others. The model will further show how academic performance is affected by internet/game addiction. The correlation among the variables 'internet/game addiction' and 'internet use' and 'gaming' (during weekdays and weekends) 
were also assessed, and they were less than 0.5 . Multicollinearity was assessed using the variance inflation factor (VIF), which was under 5 for all models, suggesting no multicollinearity ${ }^{47}$.

$p$ value below the threshold of 0.05 was considered the threshold of significance. All analysis was conducted in $R$ (version 3.6.1). R-package survey (version 3.37) was used for modelling which is suited for complex survey samples ${ }^{48}$.

\section{Data availability}

The authors declare that they do not have permission to share dataset. However, the datasets of Young Minds Matter (YMM) survey data is available at the Australian Data Archive (ADA) Dataverse on request (https://doi. org/10.4225/87/LCVEU3).

Received: 28 August 2020; Accepted: 2 December 2020

Published online: 10 December 2020

\section{References}

1. Wang, C. -W., Chan, C. L., Mak, K. -K., Ho, S. -Y., Wong, P. W. \& Ho, R. T. Prevalence and correlates of video and Internet gaming addiction among Hong Kong adolescents: a pilot study. Sci. World J. 2014 (2014).

2. Anderson, E. L., Steen, E. \& Stavropoulos, V. Internet use and problematic internet use: a systematic review of longitudinal research trends in adolescence and emergent adulthood. Int. J. Adolesc. Youth 22, 430-454 (2017).

3. Oliveira, M. P. MTd. et al. Use of internet and electronic games by adolescents at high social risk. Trends Psychol. 25, 1167-1183 (2017).

4. UNICEF. Children in a digital world. United Nations Children's Fund (UNICEF) (2017)

5. King, D. L. et al. The impact of prolonged violent video-gaming on adolescent sleep: an experimental study. J. Sleep Res. 22, 137-143 (2013).

6. Byrne, J. \& Burton, P. Children as Internet users: how can evidence better inform policy debate?. J. Cyber Policy. 2, 39-52 (2017).

7. Council, O. Children, adolescents, and the media. Pediatrics 132, 958 (2013).

8. Paulus, F. W., Ohmann, S., Von Gontard, A. \& Popow, C. Internet gaming disorder in children and adolescents: a systematic review. Dev. Med. Child Neurol. 60, 645-659 (2018).

9. Posso, A. Internet usage and educational outcomes among 15-year old Australian students. Int J Commun 10, 26 (2016).

10. ABS. 8146.0-Household Use of Information Technology, Australia, 2016-2017 (2018).

11. Brand, J. E. Digital Australia 2018 (Interactive Games \& Entertainment Association (IGEA), Eveleigh, 2017).

12. Rikkers, W., Lawrence, D., Hafekost, J. \& Zubrick, S. R. Internet use and electronic gaming by children and adolescents with emotional and behavioural problems in Australia-results from the second Child and Adolescent Survey of Mental Health and Wellbeing. BMC Public Health 16, 399 (2016).

13. Jackson, L. A., Von Eye, A., Witt, E. A., Zhao, Y. \& Fitzgerald, H. E. A longitudinal study of the effects of Internet use and videogame playing on academic performance and the roles of gender, race and income in these relationships. Comput. Hum. Behav. 27, 228-239 (2011).

14. Yu, M. \& Baxter, J. Australian children's screen time and participation in extracurricular activities. Ann. Stat. Rep. 2016, 99 (2015).

15. Rainie, L. \& Horrigan, J. A decade of adoption: How the Internet has woven itself into American life. Pew Internet and American Life Project. 25 (2005).

16. Drummond, A. \& Sauer, J. D. Video-games do not negatively impact adolescent academic performance in science, mathematics or reading. PLoS ONE 9, e87943 (2014).

17. Green, L., Olafsson, K., Brady, D. \& Smahel, D. Excessive Internet use among Australian children (2012).

18. Livingstone, S. EU kids online. The international encyclopedia of media literacy. 1-17 (2019).

19. Wright, J. The effects of video game play on academic performance. Mod. Psychol. Stud. 17, 6 (2011).

20. Gentile, D. A., Lynch, P. J., Linder, J. R. \& Walsh, D. A. The effects of violent video game habits on adolescent hostility, aggressive behaviors, and school performance. J. Adolesc. 27, 5-22 (2004).

21. Rosenthal, R. \& Jacobson, L. Pygmalion in the classroom. Urban Rev. 3, 16-20 (1968).

22. Willoughby, T. A short-term longitudinal study of Internet and computer game use by adolescent boys and girls: prevalence, frequency of use, and psychosocial predictors. Dev. Psychol. 44, 195 (2008).

23. Weis, R. \& Cerankosky, B. C. Effects of video-game ownership on young boys' academic and behavioral functioning: a randomized, controlled study. Psychol. Sci. 21, 463-470 (2010).

24. Howell, D. C. The treatment of missing data. The Sage handbook of social science methodology. 208-224 (2007).

25. Terry, M. and Malik, A. Video gaming as a factor that affects academic performance in grade nine. Online Submission (2018).

26. Houghton, S. et al. Virtually impossible: limiting Australian children and adolescents daily screen based media use. BMC Public Health. 15, 5 (2015).

27. Jackson, L. A., Von Eye, A., Fitzgerald, H. E., Witt, E. A. \& Zhao, Y. Internet use, videogame playing and cell phone use as predictors of children's body mass index (BMI), body weight, academic performance, and social and overall self-esteem. Comput. Hum. Behav. 27, 599-604 (2011).

28. Bowers, A. J. \& Berland, M. Does recreational computer use affect high school achievement?. Educ. Technol. Res. Dev. 61, 51-69 (2013).

29. Wittwer, J. \& Senkbeil, M. Is students' computer use at home related to their mathematical performance at school?. Comput. Educ. 50, 1558-1571 (2008).

30. Jackson, L. A. et al. Does home internet use influence the academic performance of low-income children?. Dev. Psychol. 42, 429 (2006).

31. Barlett, C. P., Anderson, C. A. \& Swing, E. L. Video game effects-confirmed, suspected, and speculative: a review of the evidence. Simul. Gaming 40, 377-403 (2009).

32. Suziedelyte, A. Can video games affect children's cognitive and non-cognitive skills? UNSW Australian School of Business Research Paper (2012).

33. Chiu, S.-I., Lee, J.-Z. \& Huang, D.-H. Video game addiction in children and teenagers in Taiwan. CyberPsychol. Behav. 7, 571-581 (2004).

34. Skoric, M. M., Teo, L. L. C. \& Neo, R. L. Children and video games: addiction, engagement, and scholastic achievement. Cyberpsychol. Behav. 12, 567-572 (2009).

35. Leung, L. \& Lee, P. S. Impact of internet literacy, internet addiction symptoms, and internet activities on academic performance. Soc. Sci. Comput. Rev. 30, 403-418 (2012).

36. Xin, M. et al. Online activities, prevalence of Internet addiction and risk factors related to family and school among adolescents in China. Addict. Behav. Rep. 7, 14-18 (2018). 
37. Lawrence, D., Johnson, S., Hafekost, J., et al. The mental health of children and adolescents: report on the second Australian child and adolescent survey of mental health and wellbeing (2015).

38. Hafekost, J. et al. Methodology of young minds matter: the second Australian child and adolescent survey of mental health and wellbeing. Aust. N. Z. J. Psychiatry 50, 866-875 (2016).

39. Australian Curriculum ARAA. National Assessment Program Literacy and Numeracy: Achievement in Reading, Persuasive Writing, Language Conventions and Numeracy: National Report for 2011. Australian Curriculum, Assessment and Reporting Authority (2011).

40. Daraganova, G., Edwards, B. \& Sipthorp, M. Using National Assessment Program Literacy and Numeracy (NAPLAN) Data in the Longitudinal Study of Australian Children (LSAC). Department of Families, Housing, Community Services and Indigenous Affairs (2013).

41. NAP. NAPLAN (2016).

42. Australian Curriculum ARAA. National report on schooling in Australia 2009. Ministerial Council for Education, Early Childhood Development and Youth... (2009).

43. Vu, X.-B.B., Biswas, R. K., Khanam, R. \& Rahman, M. Mental health service use in Australia: the role of family structure and socio-economic status. Children Youth Serv. Rev. 93, 378-389 (2018).

44. McCullagh, P. Generalized Linear Models (Routledge, Abingdon, 2019).

45. Gregg, P., Washbrook, E., Propper, C. \& Burgess, S. The effects of a mother's return to work decision on child development in the UK. Econ. J. 115, F48-F80 (2005).

46. Khanam, R. \& Nghiem, S. Family income and child cognitive and noncognitive development in Australia: does money matter?. Demography 53, 597-621 (2016).

47. Kutner, M. H., Nachtsheim, C. J., Neter, J. \& Li, W. Applied Linear Statistical Models (McGraw-Hill Irwin, New York, 2005).

48. Lumley T. Package 'survey'. 3, 30-33 (2015).

\section{Acknowledgements}

The authors would like to thank the University of Western Australia, Roy Morgan Research, the Australian Government Department of Health for conducting the survey, and the Australian Data Archive for giving access to the YMM survey dataset. The authors also would like to thank Dr Barbara Harmes for proofreading the manuscript.

\section{Author contributions}

M.I.I.: Methodology, Validation, Visualization, Investigation, Writing_Original draft preparation, WritingReviewing and Editing. R.K.B.: Methodology, Software, Data curation, Formal Analysis, Writing_Original draft preparation. R.K.: Conceptualization, Methodology, Supervision, Writing- Reviewing and Editing.

\section{Funding}

This research did not receive any specific Grant from funding agencies in the public, commercial, or not-forprofit sectors.

\section{Competing interests}

The authors declare no competing interests.

\section{Additional information}

Correspondence and requests for materials should be addressed to M.I.I.

Reprints and permissions information is available at www.nature.com/reprints.

Publisher's note Springer Nature remains neutral with regard to jurisdictional claims in published maps and institutional affiliations.

(i) Open Access This article is licensed under a Creative Commons Attribution 4.0 International License, which permits use, sharing, adaptation, distribution and reproduction in any medium or format, as long as you give appropriate credit to the original author(s) and the source, provide a link to the Creative Commons licence, and indicate if changes were made. The images or other third party material in this article are included in the article's Creative Commons licence, unless indicated otherwise in a credit line to the material. If material is not included in the article's Creative Commons licence and your intended use is not permitted by statutory regulation or exceeds the permitted use, you will need to obtain permission directly from the copyright holder. To view a copy of this licence, visit http://creativecommons.org/licenses/by/4.0/.

(C) The Author(s) 2020 